Hydrology and Earth System Sciences, 9(4), 279 (2005) (C) EGU

\title{
Advances in flood forecasting
}

\section{Foreword}

It is with great pleasure that I introduce the proceedings of the International Conference Advances in Flood Forecasting in Europe, held in Rotterdam 3-5 March 2003, and marking the final phase of the EU-funded research project EFFS (European Flood Forecasting System).

The European Commission's Directorate General (DG) for Research has been supporting research in the area of floods and flood forecasting since the mid-1980s through its Framework Programmes for Research and Technological Development. With a total of about 40 dedicated flood projects, approximately 45 million Euro have been invested by the EU during the fourth (FP4) and fifth (FP5) Framework Programmes.

The sixth (FP6) Framework Programme (2003-2006) is promoting a more holistic approach by encouraging research in integrated flood risk management methodologies, by combining flood hazard, vulnerability and risk assessment, the better to mitigate the consequences of floods. Particular emphasis is being placed on the application of methods and tools and their take-up by relevant end-user communities. The characterisation of the human dimension of floods and the possible impact of climate change and the occurrence of extreme events are of special importance.

Research DG has long recognised the necessity to involve users in the design of new information tools in support of European policies. In the context of the Global Monitoring for Environment and Security (GMES), the EC, in collaboration with the European Space Agency (ESA), is now creating the conditions to stimulate and structure a dialogue between the various parties involved in environmental monitoring and information production. Natural disaster monitoring including that of floods is one of the priorities of GMES, particularly with respect to issues of civil security.
EU-MEDIN (the Euro-Mediterranean Disaster Information Network) is a recent initiative of Research DG. The aim is to connect European and national disaster research efforts, while promoting the harmonisation of techniques and tools for: improved pre-disaster planning, hazard, vulnerability and risk assessment, consequence analysis integrating the environmental, economic and social impacts of disasters, damage assessment, risk perception and communication. EU-MEDIN is a vehicle through which flood research results may be accessed and exchanged easily.

The present proceedings display some of the major lessons learnt during the European flood research programmes. The results testify that European researchers are, indeed, producing high quality results, and are at the forefront of research in flood forecasting. Despite the progress to date, more studies are required, particularly in the areas of quantitative precipitation forecasts and the characterisation of uncertainties, coupling of hydrological and meteorological models, development of flash-flood forecasting methods, and use of radar for now-casting and hydrological modelling. Additional efforts are needed to transfer the technology and methods to end users, such as water management bodies and civil protection authorities, to ensure rapid flood alerts and efficient intervention.

I would like to take this opportunity to thank the editorial board and the conference organisers on the success of the Rotterdam meeting and the subsequent publication of the results in this Special Issue of Hydrology and Earth System Sciences, the hydrological research journal of the European Geosciences Union, as well as to the project participants for their hard work and dedication over the past years to further the research in flood forecasting. I remain confident that this publication will be useful for all stakeholders in flood research.

Anver Ghazi

Global Change Unit

Environment Directorate

European Commission Research Directorate General 